\title{
Armazenamento de pêssego 'Chimarrita' em atmosfera controlada e sob absorção de etileno
}

\author{
Storage of 'Chimarrita' peach in controlled atmosphere and \\ under ethylene absorption
}

\author{
Auri Brackmann ${ }^{1}$ Cristiano André Steffens ${ }^{2}$ Ricardo Fabiano Hettwer Giehl ${ }^{3}$
}

\section{RESUMO}

Foram conduzidos dois experimentos com o objetivo de avaliar o efeito de duas formas de absorção de etileno e de condições de atmosfera controlada (AC) sobre a qualidade do pêssego 'Chimarrita'. Os tratamentos do experimento 1 foram: testemunha com armazenamento refrigerado (AR); $1 \mathrm{kPa}$ de $\mathrm{O}_{2} / 3 \mathrm{kPa}$ de $\mathrm{CO}_{2}$; e $5 \mathrm{kPa}$ de $\mathrm{O}_{2} /$ $10 \mathrm{kPa}$ de $\mathrm{CO}_{2}$. No experimento 2, os mesmos tratamentos foram combinados com a absorção de etileno; absorção de etileno por filtro; e absorção de etileno por sache e sem absorção (testemunha). Tanto no experimento 1 como no experimento 2, os frutos foram armazenados na temperatura de $-0,2^{\circ} \mathrm{C}$. As avaliações realizadas após 45 dias de armazenamento refrigerado +2 dias em temperatura ambiente demonstraram que o uso de AC manteve os frutos com maior acidez titulável e reduziu a incidência de podridões e esporulação de fungos. Após os dois dias a $20^{\circ} \mathrm{C}$, os frutos armazenados em $\mathrm{AC}$ apresentaram-se mais firmes e com menor incidência de podridões e esporulação de patógenos. Os frutos mantidos na atmosfera de $5 \mathrm{kPa}$ de $\mathrm{O}_{2} / 10 \mathrm{kPa}$ de $\mathrm{CO}_{2}$ apresentaram maior incidência de lanosidade. No experimento 2, a absorção de etileno não foi eficiente na manutenção da qualidade do pêssego 'Chimarrita', mas após dois dias a $20^{\circ} \mathrm{C}$ reduziu a incidência de podridões.

Palavras-chave: pós-colheita, armazenamento, frutas de caroço.

\section{ABSTRACT}

Two experiments were carried out with the objective to evaluate the effects of two forms of ethylene absorption and controlled atmosphere (CA) storage on the quality of 'Chimarrita' peaches. The treatments of the first experiment were: control (cold storage); $1 \mathrm{kPa} \mathrm{O}_{2} / 3 \mathrm{kPa} \mathrm{CO}_{2} ;$ e $5 \mathrm{kPaO}$ $10 \mathrm{kPaCO}$. In the second experiment the same treatments were combined to ethylene absorption; either absorption using a filter or absorption using a sachet and no absorption at all. In both experiments, the fruits were stored at $-0,2^{\circ} \mathrm{C}$ for 45 days. At retrieval from storage, $C A$ conditions maintained higher titratable acidity and reduced decay incidence and pathogen sporolution. After two days at $20^{\circ} \mathrm{C}$, the fruits stored in $C A$ were firmer had less decay and sporolated lesions. Fruits stored in $5 \mathrm{kPa} \mathrm{O}_{2} / 10 \mathrm{kPa} \mathrm{CO}_{2}$ had higher wooliness incidence. In experiment 2, the ethylene absorption was not effective for quality maintenance of 'Chimarrita' peaches, but after 2 days at $20^{\circ} \mathrm{C}$, fruits stored with ethylene absorption were less decayed.

Key words: postharvest, storage, stone fruits.

\section{INTRODUÇÃO}

O pêssego é uma fruta que está apresentando grande crescimento em sua produção nos últimos anos. Este aumento na produção, associado ao curto período de safra, exige o armazenamento de parte da produção para aumentar o período de oferta. Além disto, o consumidor exige que os frutos apresentem, além de boa aparência, sabor e maior durabilidade.

O armazenamento refrigerado é o principal método utilizado para conservação de pêssegos,

\footnotetext{
${ }^{1}$ Engenheiro Agrônomo, Doutor, Departamento de Fitotecnia, Centro de Ciências Rurais (CCR), Universidade Federal de Santa Maria (UFSM), 97105-900, Santa Maria, RS. E-Mail:brackman@creta.ccr.ufsm.br. Autor para correspondência.

${ }^{2}$ Engenheiro Agrônomo, Acadêmico do Programa de Pós-graduação em Agronomia UFSM, Bolsista CAPES. Departamento de Fitotecnia, CCR, UFSM. E-mail: cristianosteffens@bol.com.br

${ }^{3}$ Acadêmico do curso de Agronomia da UFSM, Bolsista FIPE/UFSM. Departamento de Fitotecnia, CCR, UFSM. E-mail: hetgiehl@yahoo.com.br
} 
diminuindo o metabolismo e evitando a rápida deterioração. Porém, em armazenamentos mais prolongados, a acentuada perda de firmeza de polpa, a ocorrência de distúrbios fisiológicos e a incidência de podridões são os principais problemas que ocorrem durante a frigoconservação. Segundo NAVA (2001), várias tecnologias de armazenamento disponíveis para retardar o amadurecimento dos frutos vêm sendo utilizadas. Dentre estas, podem-se destacar a absorção de etileno e o armazenamento em atmosfera controlada.

Durante o armazenamento, a técnica da absorção de etileno pode retardar o amadurecimento normal que ocorre durante períodos prolongados de armazenamento a frio e prevenir as desordens fisiológicas (DONG et al., 2001). CERETTA et al. (2000) verificaram que a eliminação de etileno durante $o$ armazenamento de pêssegos 'Eldorado', em atmosfera controlada, proporcionou frutos com maior firmeza de polpa e reduziu a incidência de podridões. NAVA (2001) obteve resultados semelhantes com a absorção de etileno durante o armazenamento de pêssego 'Chiripá' em atmosfera controlada, mas em armazenamento refrigerado a eliminação do etileno não apresentou efeito sobre a qualidade dos frutos. CRISOSTO et al. (2001) também observaram que a qualidade de pêssegos da cultivar Elegant Lady, quanto à firmeza de polpa, sólidos solúveis totais e acidez titulável, não foi afetada pela exposição dos frutos ao gás etileno, durante longo período de armazenamento nas temperaturas de $0^{\circ} \mathrm{e}$ $5^{\circ} \mathrm{C}$. Estes mesmos autores e também NAVA (2001) definiram que os sintomas de lanosidade foram retardados quando armazenados em atmosfera contendo etileno em comparação com frutos armazenados em atmosfera livre de etileno.

$\mathrm{O}$ armazenamento em atmosfera controlada é muito utilizado comercialmente no Brasil para o armazenamento de maçãs e kiwi. Na Europa e nos EUA, a atmosfera controlada é a técnica mais comumente utilizada no armazenamento de frutas de caroço. A redução dos níveis de $\mathrm{O}_{2}$ e o incremento dos níveis de $\mathrm{CO}_{2}$ retardam o amadurecimento dos frutos (LANA \& FINGER, 2000), alteram o metabolismo de pigmentos (BEAUDRY, 1999), reduzem a síntese e a ação do etileno sobre o metabolismo dos frutos e reduzem a ocorrência de podridões (KE et al., 1991; BRACKMANN \& CHITARRA, 1998). Segundo LANA \& FINGER (2000), os níveis mínimos de $\mathrm{O}_{2}$ e máximos de $\mathrm{CO}_{2}$ são limitados pela sensibilidade dos tecidos à indução da respiração anaeróbica e injúria por $\mathrm{CO}_{2}$, respectivamente, sendo variável de acordo com a cultivar. De acordo com KADER (1989), pêssegos toleram concentração mínima de $2 \mathrm{kPa} \mathrm{O}_{2}$ e máximo de $5 \mathrm{kPa}$ de $\mathrm{CO}_{2}$. ERIS et al. (1994) obtiveram melhor qualidade de frutos com $2 \mathrm{kPa}$ de $\mathrm{O}_{2}$ com $5 \mathrm{kPa}$ ou $10 \mathrm{kPa}$ de $\mathrm{CO}_{2}$. CERETTA et al. (2000) concluíram que a melhor condição de $\mathrm{AC}$ para o pêssego ‘Eldorado' é $1 \mathrm{kPa}$ de $\mathrm{O}_{2}$ e $3 \mathrm{kPa}$ de $\mathrm{CO}_{2}$. NAVA (2001), por sua vez, concluiu que esta condição apenas previne os sintomas de lanosidade em pêssego 'Chiripá', armazenado em períodos prolongados.

Para avaliar, então, a eficiência de condições de armazenamento em atmosfera controlada foi realizado o presente trabalho. Objetivou-se também determinar os efeitos de duas formas de eliminação do etileno na manutenção das qualidades físico-químicas e ocorrência de podridões e desordens fisiológicas em pêssegos cultivar Chimarrita.

\section{MATERIAL EMÉTODOS}

Os experimentos foram conduzidos no Núcleo de Pesquisa em Pós-Colheita (NPP) do departamento de Fitotecnia da Universidade Federal de Santa Maria, RS. Foram utilizados frutos da cultivar Chimarrita, provenientes de um pomar comercial do município de Farroupilha, RS.

O armazenamento foi realizado em minicâmaras experimentais de atmosfera controlada, com volume de 232 litros, as quais foram conectadas por tubulações plásticas a uma mesa de controle com analisadores de gases. $\mathrm{O}$ monitoramento da temperatura foi realizado diariamente utilizando termômetros de mercúrio introduzidos na polpa de frutos, apresentando uma oscilação de $\pm 0,2^{\circ} \mathrm{C}$. A umidade relativa (UR) das câmaras de atmosfera controlada foi aferida semanalmente com um psicrômetro, que permanecia no interior das minicâmaras, e mantida em torno de $97 \%$.

Os tratamentos no experimento 1 , consistiram nos seguintes regimes de armazenamento: $1 \mathrm{kPa} \mathrm{O}_{2} / 3 \mathrm{kPa} \quad \mathrm{CO}_{2}, 5 \mathrm{kPa} \mathrm{O}_{2} / 10 \mathrm{kPa} \quad \mathrm{CO}_{2}$; e armazenamento refrigerado (AR). No experimento 2 , os tratamentos utilizados foram: sem absorção de etileno; absorção de etileno com sache; e absorção de etileno com filtro de vermiculita impregnada com permanganato de potássio, sendo os frutos armazenados na temperatura de $-0,2^{\circ} \mathrm{C}$, em ambos os experimentos.

No experimento 1, as pressões parciais dos gases foram obtidas através da instalação da atmosfera pela diluição do $\mathrm{O}_{2}$ nas minicâmaras com injeção de $\mathrm{N}_{2}$, proveniente de um gerador de nitrogênio, que utiliza o princípio de peneira molecular ("Pressure Swing Adsorption" - PSA), e posterior injeção de $\mathrm{CO}_{2}$, proveniente de cilindros de alta pressão, até atingir os níveis estabelecidos nos tratamentos. A manutenção das pressões parciais desejadas dos gases nas diferentes câmaras, que variavam em função da 
respiração dos frutos, foi através da análise diária com uso de analisadores eletrônicos de $\mathrm{CO}_{2}$ e $\mathrm{O}_{2}$, marca Agri-datalog e posterior correção das pressões parciais até os níveis preestabelecidos nos tratamentos. $\mathrm{O} \mathrm{O}_{2}$ consumido pela respiração foi reposto através da injeção de ar atmosférico nas minicâmaras. $\mathrm{O} \mathrm{CO}_{2} \mathrm{em}$ excesso foi absorvido por uma solução de hidróxido de potássio (40\%), através da qual foram circulados os gases das minicâmaras.

No experimento 2, a absorção de etileno foi realizada com a absorção deste gás por filtro e sache, ambos contendo vermiculita impregnada com permanganato de potássio na concentração de $5 \%$. No tratamento com absorção de etileno através de filtro, o ar da câmara foi constantemente circulado pelo filtro com uma bomba de membrana com fluxo de $240 \mathrm{~L} \mathrm{~h}^{-1}$.

Após 45 dias de armazenamento e mais dois dias de exposição dos frutos à temperatura de $20^{\circ} \mathrm{C}$, foram realizadas as avaliações. A firmeza de polpa e a incidência de distúrbios fisiológicos foram determinadas para cada fruto, enquanto os sólidos solúveis totais (SST) e a acidez titulável foram determinados no suco extraído das amostras de 15 frutos. A firmeza de polpa foi determinada em dois lados na parte equatorial do fruto, a partir da retirada da epiderme, com auxílio de um penetrômetro motorizado com ponteira de 7,9mm de diâmetro. O teor de SST foi determinado com auxílio de um refratômetro manual, com correção da temperatura. A acidez titulável foi determinada através de titulação de $10 \mathrm{ml}$ de suco diluídos em $100 \mathrm{ml}$ de água destilada, com solução de $\mathrm{NaOH} 0,1 \mathrm{~N}$ até $\mathrm{pH} 8,1$. Na avaliação de ocorrência de podridões, frutos com lesões de diâmetro superior ou igual a $0,5 \mathrm{~cm}$, com características de ataques de patógenos, foram considerados podres. O escurecimento interno da polpa foi determinado através da contagem de frutos com qualquer tipo de escurecimento interno na polpa. A incidência de lanosidade foi determinada de forma subjetiva através do pressionamento dos frutos entre os dedos e pela visualização direta da presença ou ausência de suco e ou polpa farinácea. Os dados foram submetidos à análise de variância e as médias comparadas pelo teste de Duncan em nível de 5\% de probabilidade de erro sendo que os dados em porcentagem foram transformados através da fórmula arcsen $\sqrt{\mathrm{x} / 100}$.

\section{RESULTADOS E DISCUSSÃO}

Após 45 dias de armazenamento, no primeiro ensaio observou-se que, na saída da câmara, não houve diferença entre os tratamentos para o parâmetro firmeza de polpa (Tabela 1). Já após dois dias de exposição dos frutos a $20^{\circ} \mathrm{C}$, a firmeza de polpa foi superior nos frutos armazenados em atmosfera controlada (Tabela 1). RUSHING \& DINAMARCA (1993) determinaram o mesmo efeito em frutos armazenados em atmosfera controlada. Entretanto, PURVIS (1993) não observou diferença estatística entre frutos armazenados em AR e atmosfera controlada, para o parâmetro firmeza de polpa.

A acidez titulável, na saída da câmara, foi maior nos frutos armazenados em atmosfera controlada (Tabela 1). NAVA (2001) também obteve acidez mais elevada em frutos armazenados em atmosfera controlada. Esta redução na degradação dos ácidos pela atmosfera controlada possivelmente esteja relacionada à ação do $\mathrm{CO}_{2}$ sobre a inibição das enzimas aconitase, isocitrato desidrogenase e succinase desidrogenase do ciclo dos ácidos tricarboxílicos. $\mathrm{Na}$ análise realizada após dois dias de exposição dos frutos a $20^{\circ} \mathrm{C}$, não foi observada diferença entre os tratamentos (Tabela 1).

Os valores de sólidos solúveis totais (SST) foram maiores nos frutos armazenados em AR, na saída da câmara, e em 5,0kPa de $\mathrm{O}_{2}$ associado com $10 \mathrm{kPa}$ de $\mathrm{CO}_{2}$, após dois dias de exposição dos frutos a $20^{\circ} \mathrm{C}$ (Tabela 1). Entretanto, NAVA (2001) não observou efeito de condições de atmosfera controlada sobre os sólidos solúveis totais. De acordo com CERETTA et al. (2000), os sólidos solúveis totais apresentam pequenas variações durante o armazenamento, e os aumentos que são determinados podem ser explicados pelas perdas de umidade dos frutos.

A ocorrência de podridões e esporulação de patógenos foi menor nos frutos armazenados em atmosfera controlada, tanto na saída da câmara como após dois dias de exposição dos frutos à temperatura de $20^{\circ} \mathrm{C}$ (Tabela 1). CERETTA et al. (2000) também obtiveram menor ocorrência de podridões com o uso da atmosfera controlada. De acordo com BRACKMANN \& CHITARRA (1998), o efeito na redução da ocorrência de podridões em atmosfera controlada é devido ao retardamento da degradação de pectinas da parede celular, tornando o fruto mais resistente à incidência de fungos.

A ocorrência de escurecimento de polpa somente foi observada após dois dias de exposição dos frutos a $20^{\circ} \mathrm{C}$ e apenas nos frutos armazenados em ar refrigerado, embora não tenham ocorrido diferenças significativas entre tratamentos (Tabela 1). NAVA (2001) afirma que este distúrbio fisiológico é decorrente de baixas temperaturas de armazenamento, devido ao acúmulo de substâncias tóxicas, mas não observou escurecimento da polpa em pêssego 'Chiripá' na temperatura de $-0,5^{\circ} \mathrm{C}$. 
Tabela 1 - Qualidades físico-químicas e ocorrência de distúrbios físiológicos e podridões em pêssegos 'Chimarrita', após 45 dias armazenamento a $-0,2^{\circ} \mathrm{C}$. Santa Maria, 1999.

\begin{tabular}{|c|c|c|c|c|c|c|c|c|}
\hline & $\mathrm{O}_{2} / \mathrm{CO}_{2}(\mathrm{kPa})$ & $\begin{array}{l}\text { Firmeza de } \\
\text { polpa }(\mathrm{N})\end{array}$ & $\begin{array}{l}\text { Acidez Titulável } \\
\left(\mathrm{cmol} . \mathrm{L}^{-1}\right)\end{array}$ & $\begin{array}{c}\text { SST } \\
\left({ }^{\circ} \text { Brix }\right)\end{array}$ & $\begin{array}{l}\text { Podridão } \\
(\%)\end{array}$ & $\begin{array}{c}\text { Frutos com } \\
\text { esporulação }(\%)\end{array}$ & $\begin{array}{c}\text { Escurecimento } \\
\text { de polpa }(\%)\end{array}$ & $\begin{array}{c}\text { Lanosidade } \\
(\%)\end{array}$ \\
\hline \multirow{5}{*}{$\begin{array}{l}\text { Saída da } \\
\text { câmara }\end{array}$} & Testemunha & $69,8 \mathrm{a}$ & $4,70 \mathrm{~b}$ & $11,1 \mathrm{a}$ & $41,7 \mathrm{a}$ & $16,7 \mathrm{a}$ & $0,0 \mathrm{a}$ & $0,0 \mathrm{a}$ \\
\hline & $5,0 / 10,0$ & $68,9 a$ & $5,69 \mathrm{a}$ & $10,3 b$ & $1,7 \mathrm{~b}$ & $0,0 \mathrm{~b}$ & $0,0 \mathrm{a}$ & $0,0 \mathrm{a}$ \\
\hline & $1,0 / 3,0$ & 71,6 & $5,77 \mathrm{a}$ & $10,8 \mathrm{ab}$ & $5,0 \mathrm{~b}$ & $0,0 \mathrm{~b}$ & $0,0 \mathrm{a}$ & $0,0 \mathrm{a}$ \\
\hline & Coef. variação & 3,01 & 9,81 & 2,66 & 60,46 & 62,97 & 0,0 & 0,0 \\
\hline & Testemunha & $17,6 \mathrm{~b}$ & $5,73 \mathrm{a}$ & $10,9 \mathrm{~b}$ & $93,3 \mathrm{a}$ & $80,0 \mathrm{a}$ & $2,5 \mathrm{a}$ & $15,5 \mathrm{~b}$ \\
\hline \multirow{3}{*}{$\begin{array}{c}\text { Dois } \\
\text { dias a } \\
20^{\circ}\end{array}$} & $5,0 / 10,0$ & $23,2 \mathrm{a}$ & $5,20 \mathrm{a}$ & $11,6 \mathrm{a}$ & $61,7 b$ & $51,7 \mathrm{ab}$ & $0,0 \mathrm{a}$ & $45,0 \mathrm{a}$ \\
\hline & $1,0 / 3,0$ & $21,4 \mathrm{ab}$ & $5,24 \mathrm{a}$ & $10,8 b$ & $36,7 b$ & $16,0 \mathrm{~b}$ & $0,0 \mathrm{a}$ & $5,0 \mathrm{c}$ \\
\hline & Coef. variação & 14,06 & 9,70 & 2,72 & 26,09 & 40,11 & 81,01 & 19,42 \\
\hline
\end{tabular}

* Tratamentos com médias não seguidas pelas mesmas letras, em cada avaliação, diferem estatisticamente entre si, pelo teste de Duncan em nível de $5 \%$ probabilidade de erro.

A ocorrência de lanosidade não foi observada na avaliação realizada na saída da câmara (Tabela 1). Já após dois dias de exposição dos frutos a $20^{\circ} \mathrm{C}$, observou-se que a condição de armazenamento de $5 \mathrm{kPa}$ de $\mathrm{O}_{2}$ associado a $10 \mathrm{kPa}$ de $\mathrm{CO}_{2}$, proporcionou maior incidência de frutos com este distúrbio, e que frutos armazenados em $1 \mathrm{kPa}$ de $\mathrm{O}_{2}$ associado com $3 \mathrm{kPa}$ de $\mathrm{CO}_{2}$ apresentaram menor incidência de lanosidade (Tabela 1). PURVIS (1993) e NAVA (2001) também obtiveram maior incidência de lanosidade em pêssegos 'Chiripá' armazenados em 10kPa de $\mathrm{CO}_{2}$. De acordo com Von MOLLENDORFF et al. (1993), o fenômeno da lanosidade é a gelatinização da água pelas pectinas, sendo que PURVIS (1993) verificou menos suco em frutos com alta quantidade de pectina solúvel em água.

Nas avaliações realizadas na saída da câmara dos frutos do segundo experimento, não foi observada diferença entre os tratamentos em todos os parâmetros avaliados (Tabela 2). Estes resultados estão de acordo com CRISOSTO et al. (2001), que afirma que os atributos de qualidade em pêssegos não são influenciados pela exposição contínua a 3ppb de etileno. NAVA (2001) também não verificou efeito da eliminação do etileno sobre a qualidade de pêssegos 'Chiripá' em frigoconservação. Muitos trabalhos relatam a obtenção de maior firmeza de polpa quando se elimina etileno em armazenamento em atmosfera controlada. Entretanto, NAVA (2001) acredita que este efeito do etileno possa estar relacionado com o incremento da lanosidade. Segundo LUCHSINGER (2000), um dos sintomas que se verifica em frutos é o espessamento da parede celular, o que aumenta a resistência dos tecidos.

Nas avaliações realizadas após dois dias de exposição dos frutos a $20^{\circ} \mathrm{C}$, observou-se que o uso de absorvedores de etileno reduziu a incidência de podridões, porém nas demais variáveis não foram observadas diferenças entre tratamentos (Tabela 2). O resultado da menor ocorrência de podridão com o uso de absorvedores de etileno está de acordo com CERETTA et al. (2000), que também obtiveram redução na incidência de podridões com a absorção de etileno em armazenamento em atmosfera controlada. Entretanto, o efeito da absorção do etileno sobre a redução de podridões, quando ocorre, deve estar associado à maior firmeza de polpa dos frutos, conferindo maior resistência à infecção, não exercendo

Tabela 2 - Qualidades físico-químicas e ocorrência de distúrbios fisiológicos e podridões em pêssegos 'Chimarrita', após 45 dias armazenamento a $-0,2^{\circ} \mathrm{C}$. Santa Maria, 1999.

\begin{tabular}{|c|c|c|c|c|c|c|c|c|}
\hline & Tratamentos & $\begin{array}{l}\text { Firmeza de } \\
\text { polpa }(\mathrm{N})\end{array}$ & $\begin{array}{l}\text { Acidez Titulável } \\
\left(\mathrm{cmol} . \mathrm{L}^{-1}\right)\end{array}$ & $\begin{array}{c}\mathrm{SST} \\
\left({ }^{\circ} \mathrm{Brix}\right)\end{array}$ & $\begin{array}{l}\text { Podridão } \\
(\%)\end{array}$ & $\begin{array}{c}\text { Frutos com } \\
\text { esporulação (\%) }\end{array}$ & $\begin{array}{l}\text { Escurecimento de } \\
\text { polpa }(\%)\end{array}$ & $\begin{array}{c}\text { Lanosidade } \\
(\%)\end{array}$ \\
\hline \multirow{5}{*}{$\begin{array}{l}\text { Saída da } \\
\text { câmara }\end{array}$} & Sem absorção & $69,8 \mathrm{a}$ & $4,70 \mathrm{a}$ & $11,1 \mathrm{a}$ & $41,7 \mathrm{a}$ & $16,7 \mathrm{a}$ & $0,0 \mathrm{a}$ & $0,0 \mathrm{a}$ \\
\hline & Com absorção (Filtro) & $68,8 \mathrm{a}$ & $5,05 \mathrm{a}$ & $11,2 \mathrm{a}$ & $63,3 a$ & $5,0 \mathrm{a}$ & $0,0 \mathrm{a}$ & $0,0 \mathrm{a}$ \\
\hline & Com absorção (Sache) & $69,0 \mathrm{a}$ & $5,12 \mathrm{a}$ & $10,7 \mathrm{a}$ & $43,3 \mathrm{a}$ & $16,7 \mathrm{a}$ & $0,0 \mathrm{a}$ & $0,0 \mathrm{a}$ \\
\hline & Coef. variação & 2,82 & 5,16 & 3,73 & 29,66 & 51,45 & 0,0 & 0,0 \\
\hline & Sem absorção & $17,6 a$ & $5,73 a$ & $10,9 a$ & $93,3 \mathrm{a}$ & $80,0 \mathrm{a}$ & $2,5 \mathrm{a}$ & $17,5 \mathrm{a}$ \\
\hline \multirow{3}{*}{$\begin{array}{l}\text { Dois } \\
\text { dias a } \\
20^{\circ}\end{array}$} & Com absorção (Filtro) & $17,6 \mathrm{a}$ & $6,37 \mathrm{a}$ & $11,4 \mathrm{a}$ & $81,7 \mathrm{ab}$ & $65,0 \mathrm{a}$ & $12,5 \mathrm{a}$ & $17,5 \mathrm{a}$ \\
\hline & Com absorção (Sache) & $15,0 \mathrm{a}$ & $5,73 \mathrm{a}$ & $10,8 \mathrm{a}$ & $81,0 \mathrm{~b}$ & $66,7 \mathrm{a}$ & $10,0 \mathrm{a}$ & $22,5 \mathrm{a}$ \\
\hline & Coef. variação & 12,53 & 9,74 & 4,06 & 9,14 & 18,23 & 61,09 & 40,20 \\
\hline
\end{tabular}

* Tratamentos com médias não seguidas pelas mesmas letras, em cada período de avaliação, diferem estatisticamente entre si, pelo teste de Duncan em nível de $5 \%$ de probabilidade de erro.

Ciência Rural, v. 33, n. 3, 2003. 
ação direta sobre os patógenos, o que não foi verificado neste trabalho.

\section{CONCLUSÃO}

A melhor condição de atmosfera controlada para pêssegos 'Chimarrita' é $1 \mathrm{kPa}$ de $\mathrm{O}_{2}$ combinado com $3 \mathrm{kPa}$ de $\mathrm{CO}_{2}$ e uso de absorvedores de etileno não traz benefícios na manutenção da qualidade desta cultivar.

\section{REFERÊNCIAS BIBLIOGRÁFICAS}

BEAUDRY, R.M. Effect of $\mathrm{O}_{2}$ and $\mathrm{CO}_{2}$ partial pressure on selected phenomena affecting fruit and vegetable quality. Postharvest Biology and Technology, Amsterdam, v.15, p.293-303, 1999.

BRACKMANN, A.; CHITARRA, A.B. Atmosfera controlada e atmosfera modificada. In: Armazenamento e processamento de produtos agrícolas. Lavras : UFLA/ SBEA, 1998. p.133-170.

CERETTA, M. et al. Conservação em atmosfera controlada de pêssego Eldorado. Ciência Rural, Santa Maria, v.30, n.1, p.73-79, 2000 .

CRISOSTO, C.H. et al. Understanding the role of ethylene in peach cold storage life. Acta Horticulturae, Leuven, v.553, n.1, p.287-288. 2001.

DONG, L.; ZHOU, H.W.; LURIE, S. The role of ethylene in development of storage disorders in nectarine and plum. Acta Horticulturae, Leuven, v.553, n.1, p.285-287. 2001.

ERIS, A.; TÜRKBEN, C.; ÖZER, M.H. A research on controlled atmosphere (CA) storage of peach cv. Hale Haven. Acta Horticulturae, Leuven, v.368, p.767-776, 1994

KADER, A.A. A summary of CA requeriments and recommendations for fruits other than pome fruits. In: INTERNATIONAL CONTROLLED ATMOSPHERE
RESEARCH CONFERENCE, 5., 1989, Wenatchee. Proceedings... Wenatchee : University of Idaho, 1989. V.2, p.303-328.

KE, DY.; RODRIGUEZ, S.L.; KADER, A.A. Physiologicalresponses and quality attributes of peaches kept in low oxygen atmospheres. Scientia Horticularae, Amsterdam, v.47, n.34, p.295-303, 1991.

LANA, M.M.; FINGER, F.L. Atmosfera modificada e controlada. Aplicação na conservação de produtos hortícolas. Brasília : Embrapa Hortaliças, 2000. 34p.

LUCHSINGER, L. Avanços na conservação de frutas de caroço. In: SIMPÓSIO INTERNACIONAL DE FRUTAS DE CAROÇO - PÊSSEGOS, NECTARINAS E AMEIXAS, 1., 2000, Porto Alegre. Anais... Porto Alegre : UFRGS, 2000. p.95-104.

MAZARO, S.M.; BRACKMANN, A.; STORCK, L. Qualidade de kiwi armazenado em duas temperaturas sob atmosfera controlada e com eliminação de etileno. Ciência Rural, Santa Maria, v.30, n.6, p.947-952, 2000.

NAVA, G.A. Efeito da atmosfera controlada, eliminação do etileno da câmara e do pré-resfriamento sobre a qualidade de pêssegos, cv. Chiripá. 2001. 73f. Dissertação (Mestrado em Agronomia) - Universidade Federal de Santa Maria, Santa Maria.

PURVIS, A.C. Effects of short-term CA storage on cell wall Polysaccaharides during subsequent ripening of peaches. In: INTERNATIONAL CONTROLLED ATMOSPHERE RESEARCH CONFERENCE, 6., 1993, Ithaca. Proceedings... Ithaca : Cornell University, 1993. V.1, p.418-424.

RUSHING, J.W.; DINAMARCA, A. Simulated shipment of peaches, plums, and nectarines under controlled atmospheres. In: INTERNATIONAL CONTROLLED ATMOSPHERE RESEARCH CONFERENCE, 6., 1993, Ithaca. Proceedings... Ithaca : Cornell University, 1993. V.1, p.202-222.

VON MOLLENDORFF, L.J., de et al. Molecular characteristics of pectic constituents in relation to firmness, extractable juice and woolliness in nectarines. J Amer Soc Hort Sci, v.118, p.77-80, 1993. 